\title{
OUTGOING LONG WAVE RADIATION (OLR) FROM KALPANA SATELLITE PRIOR TO NEPAL EARTHQUAKE OF APRIL 25, 2015
}

\author{
Rajesh Prakash $^{1}$, R. K. Singh ${ }^{2}$, H. N. Srivastava ${ }^{3}$ \\ ${ }^{\text {I} S c i e n t i s t, ~ I n d i a ~ M e t e o r o l o g i c a l ~ D e p a r t m e n t, ~ N e w ~ D e l h i, ~ I n d i a ~}$ \\ ${ }^{2}$ Scientist, India Meteorological Department, New Delhi, India \\ ${ }^{3}$ Addl. D. G. M. (Retd.), India Meteorological Department, New Delhi, India
}

\begin{abstract}
The recent Nepal earthquake of 25 April, 2015 (Mw:7.9) and its largest aftershock on May 12, 2015 (Mw:7.3) took a toll of about 10,000 lives in Nepal, India and Tibet besides injuries to thousands and huge destruction of property. The epicentre of the main shock was located about $80 \mathrm{~km}$ northwest of Kathmandu. Keeping in view that rise in OLR or derived thermal anomalies based on satellite and surface meteorological data prior to a few earthquakes in India and elsewhere have been reported, this paper examines the outgoing long wave radiation from Kalpana satellite from April 10 to May 12,2015 over the epicentral region of the main shock and its aftershocks. It is found that the outgoing long wave radiation prior to the main earthquake and its largest aftershock remained low similar to that reported for Sikkim earthquake( Mw 6.9) on September 18, 2011. On the other hand significant rise in OLR values occurred far away over Rajasthan and adjoining regions where no seismic activity was recorded. This marked increase in OLR values in these areas were attributed to heat wave conditions during the month of April implying that rise in thermal anomaly if any cannot be considered as earthquake precursor due to its meteorological origin.
\end{abstract}

Keywords: Nepal earthquake 2015, earthquake precursor, outgoing long wave radiation

\section{INTRODUCTION}

Of late attempts have been made to search for earthquake precursors using outgoing long wave radiation (OLR) or thermal anomalies based on infra red sensors on board different satellites or surface weather observations $(\mathrm{Zu}$ ji et al.,1991; Saraf and Chaudhury,2005; Ouzounov et al., 2007; Wei et al., 2013). Their association with earthquakes have however, been questioned due to the lack of basic physics to explain the mechanism of transfer of heat from the focal region of earthquakes to the earth's surface. Most of these studies (Saraf and Chaudhury, 2005; Saraf et al., 2012; Venkatanathan and Natyaganov, 2014) have in general not examined the influence of synoptic and dynamic meteorological changes during the precursory period which could account for the rise in OLR or thermal anomalies. Sometimes data from a single passage of satellite has been used to relate them with impending earthquake like Latur ,1993 (Srivastava et al., 1997) while the rise in temperature or OLR anomaly should show continuous rise till the occurrence of earthquake. Blacket et al. (2010) were perhaps the first to infer that claims of thermal precursors to earthquakes should be treated with caution. The occurrence of the Nepal earthquake, April 25, 2015 (Mw 7.9) and its largest aftershock on May 12, 2015 (Mw 7.3) provided an opportunity to examine the utility of OLR data obtained from the INSAT Kalpana satellite as earthquake precursor. The objective of this paper is to examine the OLR data from April 10 to 13 May, 2015 covering the Indian plate and neighbourhood to see whether any increase in OLR values could be detected prior to the main Nepal earthquake of April 25, 2015 and its largest aftershock of May 12, 2015. The locations of these earthquakes are shown in fig-1.

\section{OLR AND TEMPERATURES NEAR THE} EARTH'S SURFACE

OLR is the energy radiated from the earth as infrared radiation to space in the wavelength bands of 3-100 $\mu \mathrm{m}$. The OLR depends upon the temperature of the radiating body like earth. It is effected by the earth's skin temperature, surface emissivity, atmospheric temperature, water vapour profile, cloud cover and dust in the atmosphere. OLR is generally measured through infra red sensors in Advanced Very High Resolution Radiometers (AVHRR) of remote sensing satellites but surface weather observations are also used to validate them. The multispectral scanners in satellites generally record images in six bands ranging from 8.6 to $12.2 \mu \mathrm{m}$ from which OLR values are derived in Watts/meter ${ }^{2}$. Several satellites like Landsat, Modis, Aster, FY-2C/2E have been used to study OLR (thermal) variations in meteorology or earthquakes. In India, the OLR data from Kalpana satellite launched by Indian Space Research Organisation (ISRO), India is readily available in India Meteorological Department (IMD). Singh et al.(2007) suggested a methodology for estimating OLR using infrared window and water vapour radiances from Kalpana very high resolution radiometer and found good agreement with Meteosat -7 derived OLR. Different algorithm and calibration methods are used to drive OLR and corresponding temperature values using Planck's and Stephens - Boltzmann's laws of black body radiation. Shah et al., (2013) compared the maximum and minimum temperature data from MODIS satellite with that from the surface observations reported by India Meteorological Department (IMD) and found mean absolute error less than 
$\pm 2^{0} \mathrm{C}$ and RMSE of about $+2 \cdot 2^{0} \mathrm{C}$. For interpreting OLR or precursory thermal anomalies due weightage needs to be given to the meteorological factors such as land and sea breeze, orographic ascent or descent, troughs in westerlies or easterlies, western disturbances and or induced lows, monsoon depressions, position of axis of monsoon trough, cyclonic storms or persistence of high pressure areas, onset and withdrawal of monsoon, El Nino conditions over eastern Pacific ocean or warm ocean currents. It may be mentioned that OLR is a very important parameter in meso scale (local), regional and global models for weather forecasting along with aerosol loading, cumulus parameterisation, air sea interaction, planetary boundary layer, soil moisture and topography. Of late, attempts to use OLR data have been made for earthquake precursory research. Accordingly, regions of higher values of OLR are indicative of higher heat or rise in temperature prior to earthquake and vice versa. It appears to be interesting to examine OLR variations preceding the great Nepal earthquake, 2015 (M: 7.9) and its largest aftershock (M: 7.3).

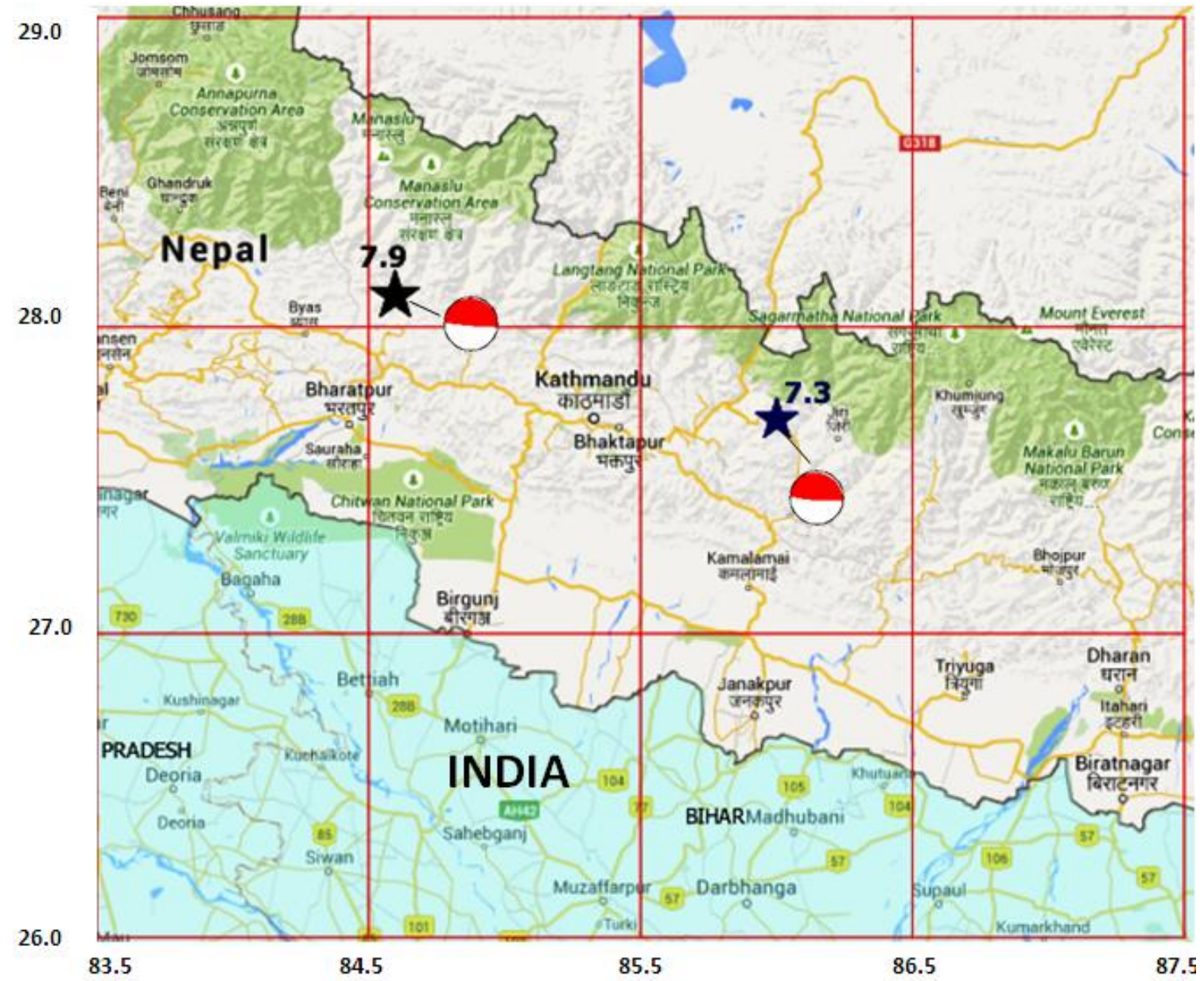

Fig-1: EPICENTRAL LOCATION OF MAIN SHOCK (APRIL 25, 2015; M:7.9) AND ITS LARGEST AFTER SHOCK (MAY 12, 2015: , M:7.3) OF NEPAL EARTHQUAKE (FAULT PLANE FROM HARVARD CMT CATALOGUE)

\section{SEISMO TECTONICS OF NEPAL}

\section{HIMALAYAS}

The whole Himalayan region has been divided into a series of longitudinal tectono - stratigraphic domains called (i) sub-Himalaya (2) Lesser Himalaya 3) Higher Himalaya and 4) Tethys Himalaya. The main tectonic features in the Nepal Himalaya consist of several north dipping thrust faults called Himalayan Frontal Thrust (HFT), Main Boundary Thrust (MBT) and Main Central Thrust (MCT). These thrusts are inferred to branch off the major basal detachment of the Himalayan thrust belt which is called the Main Himalayan Thrust (MHT). Large earthquakes of magnitude 8 or more are attributed to MHT caused by the under thrusting of the
Indian plate below the Eurasian plate. Keeping in view potential sources of great earthquakes in the collision zones of Himalaya, plausible precursory parameters need to be explored.

Nepal is seismically very active where several large/ great earthquakes have taken place in the past particularly in 1505 (M:8.1), 1833 (M: 7.6) and 1934 (Mw:8.1). Sikkim earthquake of September 18, 2011(Mw: 6.9) also caused damage and loss of life in adjoining Nepal. Largest damage occurs due to earthquakes in Kathmandu valley which is a filled lake where ground motion is amplified. The main shock (M: 7.9) and largest aftershock (M: 7.3) of Nepal earthquake, 2015 based on the data of IMD are shown in 
Figure 1. The aftershocks covered an area of 150 x $50 \mathrm{sq}$. $\mathrm{km}$. and migration of aftershocks activity eastwards triggered the largest aftershock (Mw 7.3) on May 12, 2015.
The Nepal earthquake and its largest aftershock showed shallow dipping thrust faulting oriented NNW ( USGS, Harward).

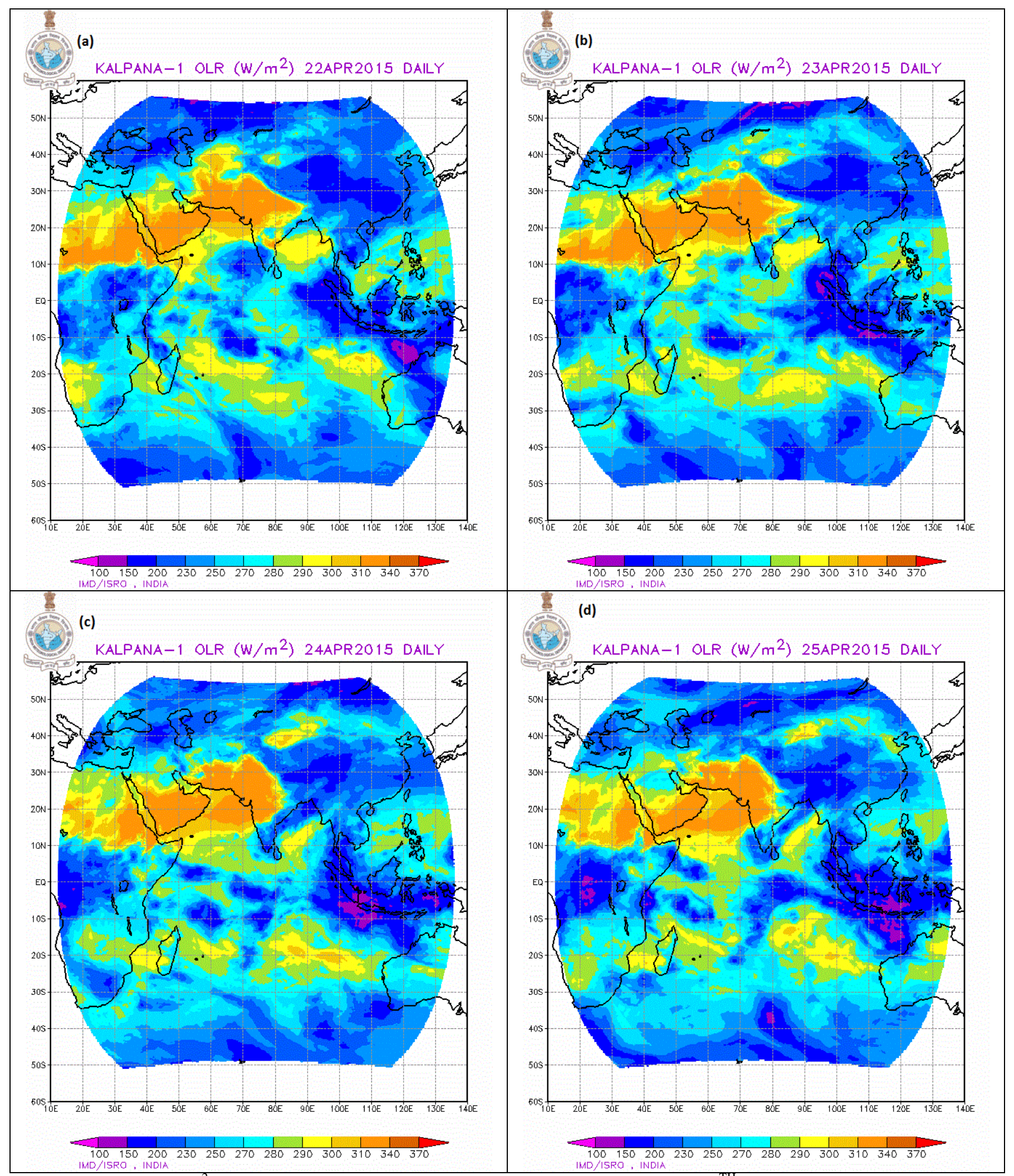

Fig-2: OLR( WATTS/M ${ }^{2}$ ) ANOMALY IN RESPECT OF NEPAL EARTHQUAKE OF $25^{\mathrm{TH}}$ APRIL 25, 2015 (FOR DAYS 2225 APRIL 2015; a, b, c, d). 


\section{OBSERVATIONS}

OLR distribution over India and neighbourhood was examined from Kalpana satellite during the period April 10, 2015 to May 12, 2015. Representative OLR anomaly in respect of main Nepal earthquake of April 25, 2015 and its largest aftershock on May 12, 2015 are shown in fig-2 (a, b, c, d) in respect of main shock; and fig-3 (a, b, c, d) for largest aftershock. On April 10, 2015,

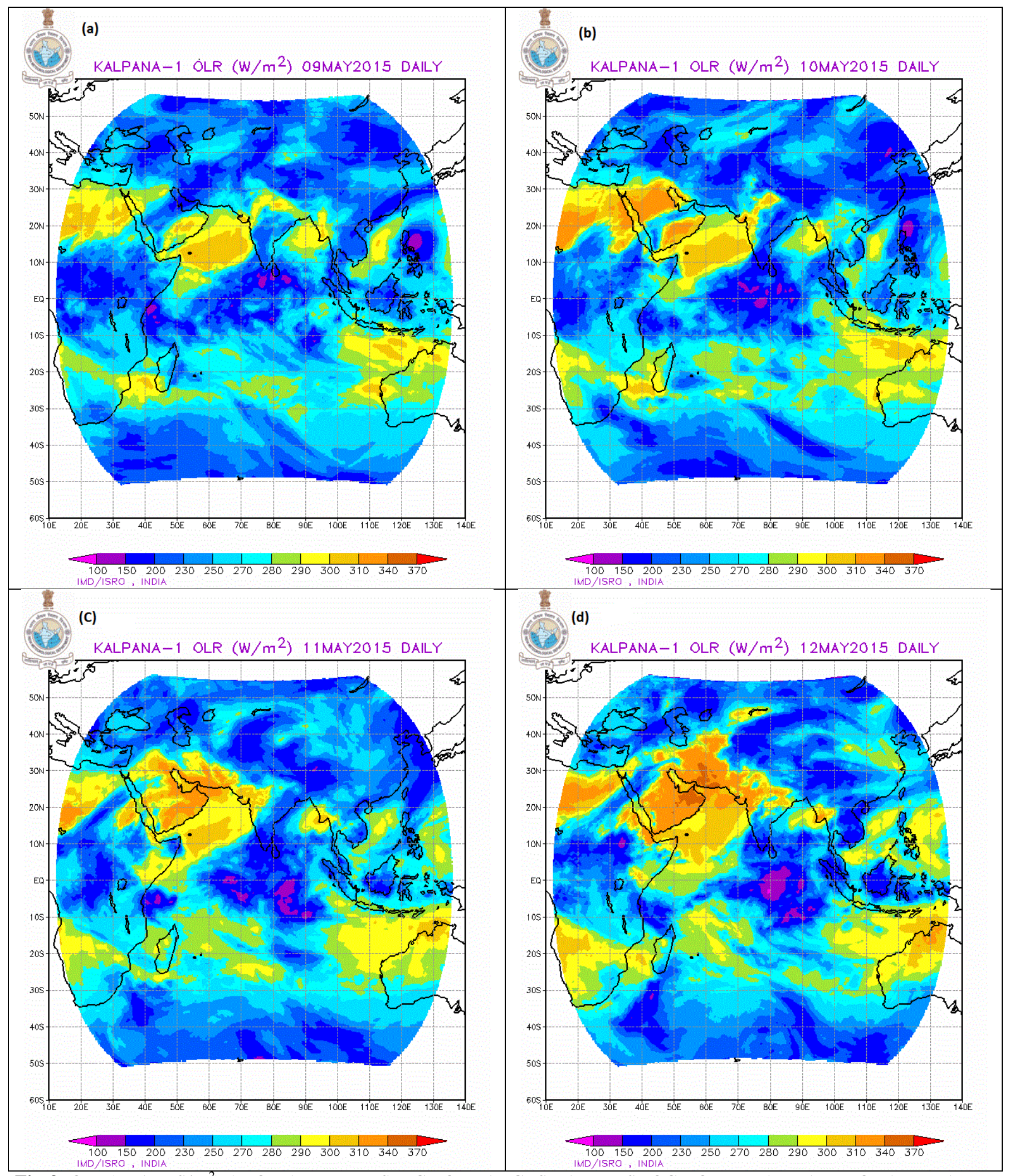

Fig-3: OLR( WATTS/M ${ }^{2}$ ) ANOMALY IN RESPECT OF LARGEST AFTERSHOCK OF NEPAL EARTHQUAKE DATED MAY 12, 2015 (FOR DAYS 09-12 MAY 2015; a, b, c, d). 

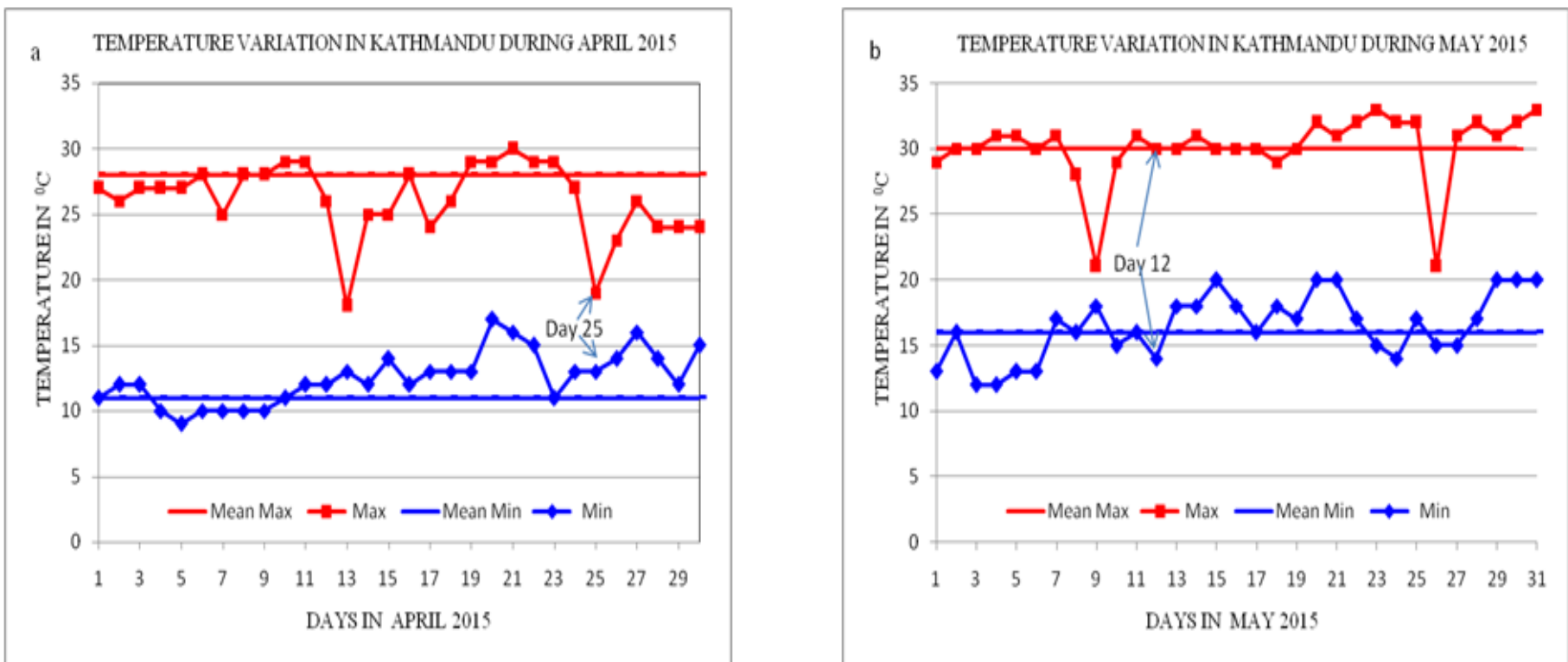

Fig-4 DAILY VARIATION OF MAXIMUM AND MINIMUM TEMPERATURES AT KATHMANDU (A: APRIL 2015; B: MAY, 2015)

OLR values of about $270 \mathrm{~W} / \mathrm{m}^{2}$ in Nepal Himalayas increasing to $300 \mathrm{~W} / \mathrm{m}^{2}$ have been found over the plains of north India and extended southeast. During the subsequent days, these values fell over the hilly regions and also in the major portion of plains of north India but increased further from Gujarat to Arabia. By April 19, 2015, the belt of high OLR values of about $300 \mathrm{~W} / \mathrm{m}^{2}$ extended over west and central India, adjoining Pakistan and further westwards. The OLR values in the impending epicentral region show decreasing trend on 22, 23, 24 April 2015 and the main Nepal earthquake occurred on April 25, 2015 in the region of very low OLR of the order of $200 \mathrm{~W} / \mathrm{m}^{2}$ (Figure 2, a-d).

Later, there was a slight increase in OLR over a thin belt running through out Himalayas on April 26, 27, and 28, 2015. On May 10, 2015 a very small pocket of higher OLR value appeared near $28^{\circ} \mathrm{N}, 80^{\circ} \mathrm{E}$ (west of main Nepal earthquake) but lower values continued over the epicentral region of the main shock or impending largest aftershock of May 12, 2015. On May 11, 2015 the region of slightly higher OLR also shifted south-westwards towards Gujarat. Also largest OLR values persisted over Arabia and neighbourhood. On May 12, 2015 when largest aftershock occurred, OLR values decreased to about $230-250 \mathrm{~W} / \mathrm{m}^{2}$ (Figure 3, a-d) in the epicentral region. There is therefore no evidence of any rise of OLR values prior to main Nepal earthquake and its largest aftershock. On the other hand much larger OLR values of the order of $270-300 \mathrm{~W} / \mathrm{m}^{2}$ occurred over Gujarat and adjoining regions extending upto Arabia where heat wave conditions are prevalent during summer months and no seismic activity was recorded.

In order to corroborate the OLR variations prior to main earthquake and its largest aftershock, the temporal variation of maximum and minimum surface temperatures at Kathmandu and their departure from long term means during April and May 2015 were examined (Fig-4). It may be noticed that day to day variability of these temperatures is very large at Kathmandu. The largest fall of $7^{\circ} \mathrm{C}$ in the maximum temperature occurred on April 13, 2015 followed by $8^{0} \mathrm{C}$ fall on April 25,2015 due to rain after the occurrence of the great Nepal earthquake April 25, 2015. The rise in the minimum temperature from April 11, 2015 reached $6^{\circ} \mathrm{C}$ above normal on April 20, 2015 and started falling thereafter to normal of $11^{0} \mathrm{C}$ two days before the earthquake. Thereafter there was marginal increase by $2^{0} \mathrm{C}$ till the occurrence of the earthquake on April 25, 2015. Later it continued to rise $1^{0}$ to $5^{0} \mathrm{C}$ above normal till the end of the month i.e 6 days after the main earthquake. During May 2015 , the lowest maximum temperature was recorded on May 10, after a sudden fall from $28^{\circ} \mathrm{C}$ on May9 and again increased from $29^{\circ} \mathrm{C}$ to $31^{\circ} \mathrm{C}$ till the occurrence of largest aftershock on May 12, 2015. It may be noted that the minimum temperature fluctuated within $1^{0} \mathrm{C}$ of the normal during this period and was lower by $2^{0} \mathrm{C}$ on the day the largest aftershock occurred.

\section{DISCUSSION}

The results presented in this study show that OLR values as measured by INSAT -Kalpana were very low at or near the epicentral region during April to May, 2015 prior to the main Nepal earthquake and its largest aftershock. It may be noticed that extensive thermal anomalies (OLR about 270$300 \mathrm{~W} / \mathrm{m}^{2}$ ) not only occurred in western India but also over a large part of Arabian desert in the month of April and May which were associated with increase in temperatures during summer months causing heat waves. It is also of interest to note that no significant seismic activity was recorded in the area of largest OLR values. Low values of OLR (150-200 $\mathrm{W} / \mathrm{m}^{2}$ ) were also found prior to the Sikkim earthquake of 2011 (Prakash and Srivastava, 2015). The surface temperatures (maximum and minimum) also corroborated these results at Kathmandu without any consistent rise above 
normal values prior to earthquakes. Close examination of surface temperatures in the epicentral regions prior to Latur (1993), Jabalpur (1997), Bhuj (2001) and Muzaffarabad (2005) and other earthquakes showed that they were within the meteorological variability caused by synoptic or dynamic changes and could not be inferred as earthquake precursor contrary to results reported earlier( Srivastava et al,1997, Saraf and Chaudhury,2005, Panda et al, 2007, Saraf et al,2012).

Saradjian and Akhoondzadeh (2011) reported thermal anomalies 1 to 20 days before a few earthquakes but pointed out that the detected thermal anomalies can be related to non seismic events. Okyay (2012) surmised that utilising LST anomalies based on 2003 Turkey earthquake observed by MODIS/Terra satellites would not be adequate and feasible since every LST anomaly is not followed by an earthquake. $\mathrm{Qu}$ (2006), found seasonal appearance of such thermal anomalies over Mongolia when examining two years NOAA 16 satellite data prior to earthquake of March 24, 2004 (Ms: 5.9). It was concluded that such anomalies are probably caused by atmosphere temperature inversion phenomena instead of earthquake. Zhang et al. (2011) by applying power spectrum technique to Japan earthquake (M: 9.0) and Myanmar earthquake (M:7.2) in March 2011 found thermal anomalies about six months before earthquakes. But their results showed that the anomaly disappeared several months prior to both these earthquakes contrary to its persistence till the occurrence of these earthquakes. The authors inferred that deep study of non seismic factors is still lacking. Blackett et al (2010) did not find convincing evidence of LST precursors to 2001 Bhuj earthquake (Mw:7.6) and urged care in indentifying seismic thermal anomalies. Prakash and Srivastava (2015) found increase in the maximum temperatures for a longer time from January 11 to January 18 in 2014 as compared to 2001 at Bhuj observatory but no earthquake occurred in 2014 inferring that anomalous rise in temperature in Gujarat prior to Bhuj earthquake, 2001 was misinterpreted as earthquake precursor. These authors did not find any relation amongst magnitude, focal depth, source mechanism, area of OLR or thermal anomaly or their duration. If single passage satellite data on early morning of 20 April 2015 is taken, it would raise a false alarm due to temporary rise in the minimum temperature at Kathmandu (Fig- 4a).

\section{CONCLUSIONS}

Analysis of OLR data obtained from Kalpana satellite over the Indian region and neighbourhood from April 10 to May 12, 2015 showed that the Nepal earthquake, 2015 and its large aftershock occurred in the region of low values of OLR. High values of OLR were found far away from Gujarat to Arabia caused by higher temperatures during summer and were not associated with any seismic activity. Low OLR values prior to Sikkim earthquake (Mw: 6.9) of September, 2011 further supported our inference. Such variations being meteorological in origin may not be considered as earthquake precursor.

\section{ACKNOWLEDGEMENTS}

The authors are grateful to India Meteorological Department for supply of data.

\section{REFERENCES}

[1] Blackett,M., M.J. Wooster, and B.D. Mahmud,(2010), Exploring land surface temperature precursors:A focus on the Gujarat(India) earthquake of 2001.Geophys.Res.Lett, 38, L15303, doi.1029/2011GL048282.

[2] Okyay U. (2012), Evaluation of thermal remote sensing for detection of thermal anomalies as earthquake precursors. A case study for Malataya Puturge Doganyol (Turkey) earthquake July 13, 2003, M S Thesis, Universitat Jaume-I, Spain.

[3] Ouzounov,D., D. Liu, K. Chunli, G. Cervone, M. Kaftos and P. Taylor,(2007), Outgoing long wave radiation variability from IR satellite data prior to major earthquakes, Tectonophysics, 431,211-220.

[4] Panda,S.K., S. Chaudhury, A. K. Saraf, and J. D. Das,(2007),Modis land surface temperature data detects thermal anomaly preceding 8 October,2005 Kashmir earthquake. Intern.J.Remote Sensing, 28,4587-4597.

[5] Prakash, Rajesh and H. N. Srivastava (2015), Thermal anomalies as related to earthquakes in India and neighbourhood, Curr. Sci., 108,11, 2071-2082

[6] Qu, C.Y.,(2006), Counter evidence for earthquake precursor of satellite thermal infrared anomalies. Chinese Journal of Geophysics, vol.49,published on line, 31 May 2006.

[7] Saradjian. M.R and Akhoondzadeh,(2011), Thermal anomalies detection before strong earthquakes, Nat.Hazards Earth,Syst.Sc,11,1099-1108.

[8] Saraf, A.K. and S. Chaudhury,(2005), NOAAAVHRR detects thermal anomaly associated with 26 January, 2001 Bhuj earthquake, Gujarat, India. Intern. Jr. Remote sensing, 26,1065-1073.

[9] Saraf,A.K., V. Rawat, J. Das, M. Zia, and K. Sharma,(2012) Satellite detection of thermal precursors of Yamnotri, Ravar and Dalbandin earthquakes. Natural Hazards,DOI 10.10007/s 11069999-011-9922-5,0n line 24 Aug 2012.

[10] Shah,D.B., M. R. Pandya, H.J.Trivedi, and A. R. Jain,(2013), Estimating minimum and maximum air temperature using MODIS data over Indo Gangetic plains. Jr.Earth system Science ,IndianAcad.Science(Springer), 122,1593-1606.

[11] Singh.R, P. K. Thapaliyal, P.M.Kishtwal, P.K.Pal, and P. K.Joshi,(2007), A new technique for estimating outgoing long wave radiances from Kalpana very high resolution radiometer, Geophys.Res.Lett,

34 , L23815, doi:10.1029/2007GL031715.

[12] Srivastava,S.K., M. Dangwal, A. Bhattacharya, and P.K. Reddy,(1997), Satellite data reveals preearthquake thermal anomalies in Killari area,Maharashtra, Curr. Sci., 72,880-885. 
[13] Venkatanathan, $\mathrm{N}$ and V. Natyaganov, (2014), Outgoing long wave radiations as preearthquake signals: preliminary results of 24 September 2013 ( M 7.7) earthquake, Curr. Sci., 106, 1291-1296.

[14] Wei,C., Y. Zhang, X.Guo, S.Hui, M.Qin, and Y. Zhang,(2013), Thermal infrared anomalies of several strong earthquakes. The Scientific World Journal, 208107,11.

[15] Zhang, Y.S, X. Guo, Cong-Xin, WEI , Wen-Rong, Shen, Shao- Xing, (2011) Hui, Characteristics of seismic thermal radiation of the Japan M 9.0 and Myanmar 7.2 earthquake, Chinese J. Geophys, 54, 670- 676.

[16] Zu-ji, Qiang, Xiu-Deng, XU and ChangGong,(1991), Dian,Thermal infrared anomaly precursor of impending earthquakes, Chinese Science Bulletin, 36,319-323.

\section{BIOGRAPHIES}

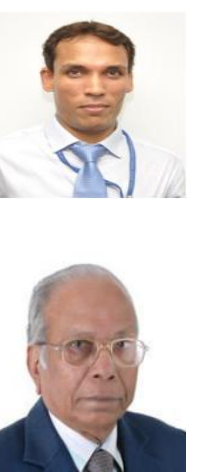

Shri R. K. Singh is working as scientist in centre for seismology, India Meteorological Department and has experience of network management and operational seismology.

Dr. H. N. Srivastava, Retd. Addl. Director General of Meteorology (Research), India Meteorological Department, emeritus scientist CSIR. He published 185 research papers and 10 books in seismology and meteorology related topics.

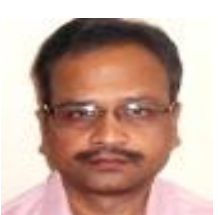

Dr. Rajesh Prakash is working as scientist in Centre for Seismology, India Meteorological Department. Published 20 research papers and two books in seismology related topics. 